\title{
Normally Grown Non-dysmorphic Stillbirth Post 38 Weeks Gestation and Reduced Fetal Movements: A Matter of Reserve? A Retrospective Study
}

\author{
Jamie Campbell $^{1}$ (D) Margaret J. Evans $^{2}$
}

Received: 4 September 2019/Accepted: 2 November 2019/Published online: 6 February 2020

(c) The Author(s) 2020

\begin{abstract}
This study investigates the relationship between placental weight relative to birthweight and risk of stillbirth in non-dysmorphic fetuses $\geq 38$ weeks gestation with no evidence of intrauterine growth restriction. This is a retrospective study of stillbirths who underwent post-mortem between 1st Jan 2011 and 31st Dec 2018 in South East Scotland $(n=55)$. The control group $(n=74)$ was matched for gestation, age of mother and maternal BMI. There was a significant difference $(p=0.0117)$ in the mean ratio of birth weight to placental weight (BW:PW) between the stillbirth group (8.17) and control group (7.33). Cases of stillbirths where the mother had reported reduced fetal movements (RFM) had a higher BW:PW compared to controls $(p=0.024)$. Within the RFM stillbirth group, 5/6 $(83 \%)$ cases showed significant changes of maternal vascular malperfusion (MVM) and/or fetal vascular malperfusion (FVM); whilst within the RFM control group, 5/15 (33\%) cases showed significant changes of MVM and/or FVM. There is a significantly higher BW:PW within the stillbirth group than within the control group, both groups show changes of MVM and/or FVM and our supposition is that these changes have a greater impact on placental reserve when the birthweight is high relative to placental weight. Reduced fetal movements may indicate diminished placental reserve. We propose that the ability to predict a high BW:PW within pregnancies where the mothers report
\end{abstract}

Margaret J. Evans

margaret.evans@nhslothian.scot.nhs.uk

1 South East Scotland Clinical Genetics Service, Centre for Genomic and Experimental Medicine, Western General Hospital, Crew Rd South, Edinburgh EH4 2XU, UK

2 Department of Pathology, Royal Infirmary of Edinburgh, Edinburgh EH16 4SA, UK
RFM may help to prevent late stillbirth in non-IUGR infants.

Keywords Stillbirth $\cdot$ Placenta $\cdot$ Pathology $\cdot$ Screening

\section{Introduction}

In 2018, Scotland recorded its lowest stillbirth rate since records began at 3.7/1000 live births [1]. Post-mortem, supplemented by genetic testing, microbiology and detailed placental assessment, is regarded as the gold standard investigation for determining cause of death in stillborn infants [2-5] and is valuable both in terms of obtaining answers for the family and improving understanding of various causes of fetal demise in utero. A systematic review of placental pathology reported in association with stillbirth showed that the proportion of stillbirths attributed to placental pathology ranged from 11 to $65 \%$, and classification systems that include placental findings reported fewer unexplained stillbirths [3].

In the last decade, the rate of stillbirth has been falling globally and nationally. In 2017, the Office of National Statistics reported a rate of 4.2/1000 live births for England and Wales with an annual reduction of $1.4 \%$ placing the UK in the lowest third of high income countries [6]. In part, the decrease is due to improved surveillance of maternal risk factors, fetal growth and appropriate timely intervention; particularly in cases of IUGR. It is however estimated that a third of stillbirths occur after 37 weeks [7] and a number of studies have shown that, despite extensive investigation, unexplained deaths are more frequent with later gestations $[8,9]$.

In the past two decades, there has been increasing interest in the significance of placental weight. A number 
of studies have shown that the placental weight and placental weight to birth weight ratio ( $\mathrm{PW}: \mathrm{BW}$ ) may be predictive of maternal disease, perinatal morbidity and mortality and childhood growth and development $[10,11]$. More recent studies have suggested that there may be a relationship between PW:BW and causes of stillbirth [12] but no group has looked specifically at BW:PW in stillbirths $\geq 38$ weeks gestation with no evidence of growth restriction [7].

Following four consecutive cases of well grown, term stillborn infants with small placentas and no identifiable cause of death or maternal risk factors at our institution. We postulate that small placentas relative to birth weight are associated with an increased risk of stillbirth and hypoxic brain injury in pregnancies $\geq 38$ weeks gestation with no IUGR. This discrepancy becomes critical as maternal vascular malperfusion (MVM) or other ageing processes further diminish placental reserve.

\section{Methods}

We conducted a retrospective case-controlled study of all structurally normal, non-growth restricted stillbirths $\geq 38$ weeks gestation born in South East Scotland between 21st Jan 2011 and 31st Dec 2018 who had been referred for post-mortem. In our referral hospitals, reduced fetal movements (RFM) were recorded from 2015. In line with the AFFIRM study mothers were asked to contact the hospital immediately if they perceived RFM, and were reminded of this at each appointment [13, 14]. Kick charts were not used as it was felt more important that mothers became familiar with their baby's movements and note any deviation from what they regarded as normal. This cohort formed the RFM subgroup (criteria for study selection are shown in Fig. 1).

We reviewed post-mortem reports and demographic data in line with Caldicott principles. This information was collated with salient clinical history, placental weight, birth weight and pathological findings. In all cases we used the weight recorded at delivery rather than the weight recorded at post-mortem when calculating $\mathrm{BW}: \mathrm{PW}$ in view of a previous study showing that any delay in carrying out the post-mortem may reduce weight [15].

This stillbirth data was compared to a cohort of consecutively received placentas $\geq 38$ weeks gestation referred for pathological examination in view of possible maternal sepsis (clinical criteria; maternal temp $>38.5{ }^{\circ} \mathrm{C} \pm$ maternal tachycardia) matched for maternal age and BMI. We excluded cases where there was a history of maternal diabetes mellitus, preeclampsia, fetal growth restriction, premature rupture of membranes and/or pathological cardiotocograph as defined by NICE [16] prior to delivery or where the infant required prolonged admission to the neonatal unit.

The placentas in the stillborn group were examined fresh and blocks taken for histology as follows; Two samples of cord, one sample of membranes and three random blocks of parenchyma. Any macroscopic lesions were also sampled [17]. Placental pathology was broadly categorized into hemorrhage (fetal maternal or abruption), infarction, acute infection, villitis of unknown etiology (VUE), chorangiosis and massive perivillous fibrin deposition (MPVFD), in accordance with Redline's classification [18]. Assigning cause of death to specific lesions can be subjective and requires clinic-pathological correlation. In line with Man et al. [19] we assigned death using criteria for Causes of Death and Associated Conditions [20.] Cause of death was attributed to feto-maternal haemorrhage if there was a positive and significant Kleihauer test. Abruption or retroplacental haemorrhage, if there was significant crater formation with adherent clot and haemorrhage, if it was temporally related to death. The significance of placental infarction was assessed by the degree of ischaemic type change noted in the background, or infarction $>50 \%$ by volume with evidence of hypoxic lesions at post-mortem. Zones of infarction $<50 \%$ were considered to cause intrauterine compromise but not necessarily death unless there were areas of full thickness infarction associated with haemorrhagic disruption of the basal plate. Acute infection was regarded as causative if there was evidence of infection at autopsy. VUE and occasional foci of fetal vascular malperfusion (previously fetal thrombotic vasculopathy) were considered contributory factors which may inform care in future pregnancies.

All routine placentas, from which the control group was derived, are formalin fixed in $10 \%$ buffered formalin solution prior to sectioning whilst stillbirth placentas are examined in the fresh state. In order to remove bias occasioned by this discrepancy we applied a correction factor of $8.4 \%$ (the largest value quoted in literature) $[21,22]$ to all the placentas in the control group; reducing their weight by this factor to allow for the possible increase in weight following formalin fixation.

We analysed BW:PW for all cases in both the stillbirth and the control groups and reviewed the placental pathology for each group.

Data was analysed in Python (version 3.7) using the library Scipy (version 1.2.0). The distribution of values for BW:PW was transformed using a Box-Cox power transformation (call scipy.stats.boxcox()) and examined for normality (call scipy.stats.normaltest()) based on D“Agostino and Pearsons test. Comparison between the groups was then carried out using independent samples $t$ test (call: scipy.stats.ttest_ind()) and a $p$ value threshold of $<0.05$ was used to mark significance. 


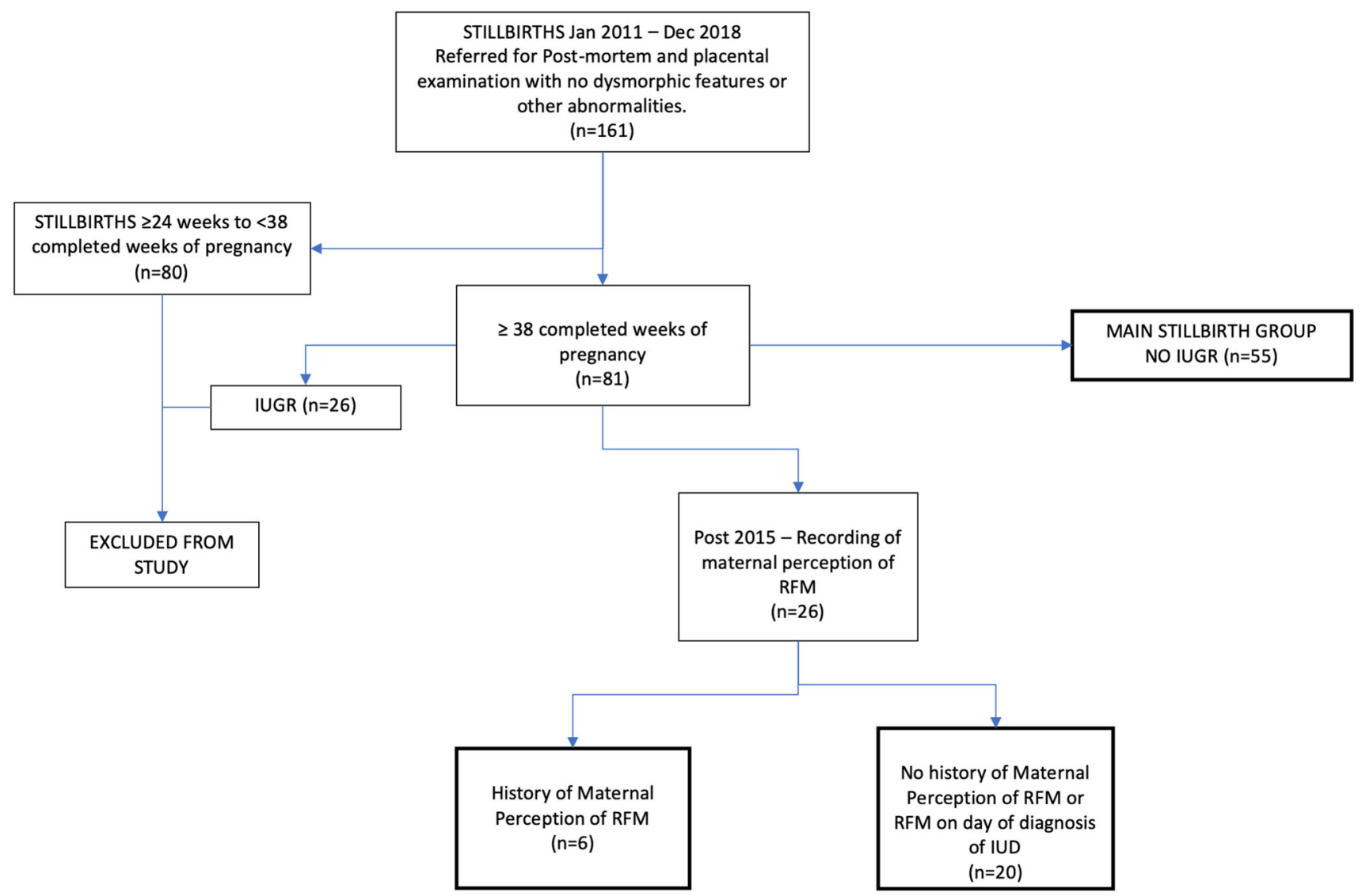

Fig. 1 Criteria for study selection. IUGR defined as weight $<10$ th centile on Intergrowth 21 st Chart - after correcting for gestational age and weight loss post intrauterine demise

\section{Results}

During the study period 161 cases of non-dysmorphic stillbirths (defined as death $\geq 24$ weeks of gestation) presented for post-mortem at this centre. 81 cases occurred at or beyond 38 completed weeks of gestation; 26 cases were excluded due to IUGR (birth weight $<10$ th centile-Intergrowth 21 st chart [23]). The remaining 55 cases formed the study's stillbirth cohort ( 31 females, 24 males). Three babies were macrosomic (weight $>95$ th centile) (Fig. 1).

There was a statistically significant difference between the BW:PW of stillborn infants $(\mathrm{n}=55)$ and the control group $(\mathrm{n}=74)(p=0.01)$. The mean characteristics of both groups are shown in Table 1.

Significant placental pathology leading to death was noted in 25 cases $(45 \%)$ summarised in Table 2. In a further five cases, pathology was noted which may have contributed to the death, including cord anomalies, hypocoiled cord of normal length $(n=3)$, hypercoiled cord with no associated pathology $(\mathrm{n}=1)$ and extensive perivillous fibrin deposition which fell short of the macroscopic criteria previously described [24] $(\mathrm{n}=1)$. The remaining 25 cases $(45 \%)$ were unexplained.
Of the 55 stillbirths, 26 occurred during the period (2015 onwards) when maternal perception of reduced fetal movements was recorded: Six cases had repeated episodes of RFM or a single episode more than 2 weeks prior to diagnosis of stillbirth. The remaining 20 cases reported no RFM or RFM only on the day that IUD was diagnosed. Of the cases reporting RFM, 5/6 (83\%) showed changes of maternal or fetal vascular malperfusion. Cases in the stillbirth group with no history of RFM or RFM on day of the intrauterine death (IUD) showed more acute pathology e.g. catastrophic haemorrhage and cord anomalies.

Within the stillbirth group the mean BW:PW was higher for those reporting RFM (9.03) than those with no RFM (8.14), but this difference did not reach statistical significance $(p=0.38)$. In the control group there was no significant difference $(p=0.77)$ in the mean BW:PW between those reporting RFM (7.23) and those with no RFM (7.38).

However, the BW:PW was higher for stillbirths with RFM (mean 9.03) than all cases without RFM (mean 7.57) $(p=0.05)$ and there was a significant difference $(p=0.02)$ between BW:PW for stillbirths with RFM (mean 9.03) and control cases with RFM (mean 7.23). In view of this difference we reviewed the pathology in both groups; 
Table 1 Mean value characteristics of stillbirth and control groups

\begin{tabular}{lllllllll}
\hline Group & $\begin{array}{l}\text { Number } \\
\text { of cases }\end{array}$ & $\begin{array}{l}\text { Maternal } \\
\text { age (years) }\end{array}$ & $\begin{array}{l}\text { Maternal } \\
\text { BMI }\end{array}$ & $\begin{array}{l}\text { Gestational } \\
\text { age (weeks) }\end{array}$ & $\begin{array}{l}\text { Birth } \\
\text { weight } \\
\text { (g) }\end{array}$ & $\begin{array}{l}\text { Placental } \\
\text { weight (g) }\end{array}$ & $\begin{array}{l}\text { Mean } \\
\text { BW:PW } \\
\text { (SD) }\end{array}$ & $\begin{array}{l}\text { Median } \\
\text { BW:PW }\end{array}$ \\
\hline Stillbirth (SB) & 55 & 30 & 26.5 & 39.7 & 3312 & 423 & $8.17(1.89)$ & 8.13 \\
Control (Ctrl) & 74 & 30 & 28 & 40 & 3700 & 517 & $7.35(1.18)$ & 7.33 \\
$\begin{array}{l}\text { Post 2015 All RFM (stillbirth } \\
\quad \text { and control groups) }\end{array}$ & 21 & 27 & 29 & 40 & 3561 & 479 & $7.75(1.58)$ & 7.5 \\
$\begin{array}{l}\text { All no RFM (stillbirth and } \\
\quad \text { control groups) }\end{array}$ & 79 & 32 & 27 & 40 & 3582 & 492 & $7.57(1.48)$ & 7.47 \\
SB RFM & 6 & 26.8 & 29.9 & 39.07 & 3071 & 356 & $9.03(2.10)$ & 8.2 \\
SB No RFM & 20 & 34.2 & 25.8 & 39.75 & 3276 & 425 & $8.14(1.92)$ & 8.26 \\
Ctrl RFM & 15 & 28 & 28 & 40 & 3757 & 527 & $7.23(0.90)$ & 7.33 \\
Ctrl No RFM & 59 & 31 & 27.5 & 40.32 & 3685 & 514 & $7.38(1.24)$ & 7.33 \\
\hline
\end{tabular}

${ }^{\mathrm{a}} \mathrm{RFM}$ - maternal perception of reduced fetal movements

Table 2 Significant pathology identified as cause of death

\begin{tabular}{|c|c|c|c|c|c|c|}
\hline $\begin{array}{l}\text { Cause of } \\
\text { death } \\
\text { identified }\end{array}$ & $\begin{array}{l}\text { Placental } \\
\text { infarction }\end{array}$ & $\begin{array}{l}\text { Placental } \\
\text { haemorrhage } \\
\text { (abruption) }\end{array}$ & Fetal vascular malperfusion & Cord accident & $\begin{array}{l}\text { Diffuse } \\
\text { VUE }\end{array}$ & $\begin{array}{l}\text { Acute } \\
\text { chorioamnionitis } \\
\text { with evidence of } \\
\text { infection }\end{array}$ \\
\hline \multirow[t]{2}{*}{$(\mathrm{n}=25)$} & $(\mathrm{n}=6)$ & $(\mathrm{n}=6)$ & $(\mathrm{n}=8)$ & $(\mathrm{n}=2)$ & $(\mathrm{n}=2)$ & $(\mathrm{n}=1)$ \\
\hline & $\begin{array}{l}\text { (1 had ruptured } \\
\text { through the } \\
\text { basal plate } \\
\text { leading to } \\
\text { catastrophic } \\
\text { haemorrhage) }\end{array}$ & & $\begin{array}{l}\text { (3 associated with cord } \\
\text { anomalies: } 2 \text { excessive } \\
\text { length and hypercoiled, } 1 \\
\text { excessive length and } \\
\text { hypocoiled, } 2 \text { with VUE) }\end{array}$ & $\begin{array}{l}\text { (1 Nuchal cord, with cord colour } \\
\text { differentiation either side of } \\
\text { compression and } 1 \text { True knot in } \\
\text { cord, with cord colour } \\
\text { differentiation either side of } \\
\text { knot) }\end{array}$ & & \\
\hline
\end{tabular}

$83 \%$ of cases presenting with RFM in the stillbirth group showed changes of maternal and/or fetal vascular malperfusion compared with $40 \%$ of cases in the control group reporting RFM. Delayed villous maturation (distal villous immaturity) [25] and chorangiosis [18], a marker of hypoxia, were seen more frequently in stillbirth cases with RFM compared to cases in the control group with RFM. The placental pathology findings of the two groups segregated by RFM history are shown in Table 3.

To evaluate whether stillbirths showed signs of hypoxia as a mechanism of death we reviewed the neuropathological findings. Twenty of the stillbirth cases (42.5\%) had detailed neuropathology and $16(80 \%)$ of these showed chronic ischaemic changes, including nuclear breakdown with karyorrhexis, and gliosis within the cortex and brain stem. The remaining 4 cases showed no significant pathological abnormality.

\section{Discussion}

A number of studies have looked at placental weight in relation to specific conditions affecting pregnancy or the relationship between placental weight, perinatal outcome and underlying disease [12, 26]. Several studies have shown that there is a positive correlation between placental weight and birth weight which is consistent across a normal population [27]. The $\mathrm{PW}: \mathrm{BW}$ is altered in complications of pregnancy particularly in fetal growth restriction [28] and there is a correlation between $\mathrm{PW}: \mathrm{BW}$ ratio $<10$ th centile and poor perinatal outcome [29].

Our study is the first to look specifically at the ratio of birth weight to placental weight in non-dysmorphic, well grown stillbirths $\geq 38$ weeks with no evidence of maternal disease and no explanation for the intrauterine death and proposes that babies with no evidence of IUGR may be at risk if the placenta is small relative to birth weight and affected by changes of maternal or fetal vascular malperfusion. 
Table 3 Placental pathology: Stillbirth and Control groups with and without RFM

\begin{tabular}{|c|c|c|c|c|c|c|c|c|}
\hline Group & $\begin{array}{l}\text { Cases } \\
\text { number }\end{array}$ & $\begin{array}{l}\text { Mean } \\
\text { BW:PW } \\
(\mathrm{SD})\end{array}$ & Median & $\begin{array}{l}\text { Maternal } \\
\text { vascular } \\
\text { malperfusion }\end{array}$ & $\begin{array}{l}\text { Delayed } \\
\text { villous } \\
\text { maturation }\end{array}$ & VUE & $\begin{array}{l}\text { Fetal vascular } \\
\text { malperfusion }\end{array}$ & Chorangiosis \\
\hline Stillbirth (SB) & 55 & $8.17(1.89)$ & 8.13 & $17(30 \%)$ & $17(30 \%)$ & $8(15 \%)$ & $11(20 \%)$ & $5(9 \%)$ \\
\hline Control (Ctrl) & 74 & $7.35(1.18)$ & 7.33 & $34(46 \%)$ & $16(21 \%)$ & $\begin{array}{l}10 \\
(13.5 \%)\end{array}$ & $3(4 \%)$ & $11(15 \%)$ \\
\hline $\begin{array}{l}\text { Post } 2015 \text { all RFM } \\
\text { (Stillbirth and control } \\
\text { groups) }\end{array}$ & 21 & $7.75(1.58)$ & 7.5 & $8(38 \%)$ & $7(33 \%)$ & $3(14 \%)$ & $3(14 \%)$ & $6(28 \%)$ \\
\hline $\begin{array}{l}\text { All no RFM (Stillbirth and } \\
\text { control groups) }\end{array}$ & 79 & $7.57(1.48)$ & 7.47 & $34(43 \%)$ & $18(22 \%)$ & $9(11 \%)$ & $4(5 \%)$ & $8(10 \%)$ \\
\hline SB RFM & 6 & 26.8 & 29.9 & $3(50 \%)$ & $3(50 \%)$ & 0 & $2(33 \%)$ & $4(66 \%)$ \\
\hline Ctrl RFM & 15 & 28 & 28 & $5(33 \%)$ & $4(26 \%)$ & $3(45 \%)$ & $1(6 \%)$ & $2(13 \%)$ \\
\hline
\end{tabular}

RFM-maternal perception of reduced fetal movements

We found that BW:PW was significantly higher in the stillborn group even though we were unable to consistently correct for the in utero reduction in weight as a consequence of maceration. As a reduction in weight might be expected with death in utero some while prior to delivery, the BW:PW ratio would have been expected to be even higher in the stillbirth group. Pinar indicated that the time interval between delivery and post mortem may lead to a reduction in weight [15]. The ongoing effect of fluid loss post-delivery in cases of maceration was partly negated in this study by using the delivery weight rather than the one recorded at post-mortem.

Our study showed no specific correlation between placental pathology and BW:PW with $50 \%$ of all cases within the stillbirth group and the control group showing changes of maternal/fetal vascular malperfusion (MVM or FVM) [17]. The similarity in pathology between the two groups suggests that changes of MVM may be physiological and related to aging of the placenta.

Our supposition is that physiological changes reduce the functional reserve of the placenta as it progresses to term and beyond and when the placenta is disproportionately small for the size of the fetus may lead to critical compromise and hypoxic episodes in utero. In keeping with this, $80 \%$ of stillbirth cases undergoing neuropathological examination showed changes of chronic intrauterine hypoxia. We further analysed this data with reference to RFM but owing to the small numbers within the study we cannot comment further on the relationship between RFM and hypoxia; though it is interesting to note that chorangiosis, regarded as a marker of hypoxia was seen more frequently in stillbirths with previously reported RFM. This requires further prospective study.

Our findings corroborate those of Janthanaphan et al. who noted that raised $\mathrm{BW}: \mathrm{PW}$ (PW:BW, 10th centile) is associated with poor perinatal outcome. This leads us to ask how we might predict falling/diminished placental reserve? Could maternal perception of reduced fetal movements (RFM) help to distinguish the "at risk" population?

In recent years there has been increased interest in RFM as a possible marker of intrauterine compromise and placental insufficiency [30.] In our study 6 cases of stillbirth presented with maternal perception of reduced fetal movements but with no other significant markers of compromise e.g. pathological CTG, fetal growth restriction or decreased liquor volume. There was a nominally significant difference ( $p=0.05)$ in $\mathrm{BW}: \mathrm{PW}$ between those in the stillbirth group reporting RFM (mean 9.03) and all the other cases without RFM (7.57) and also between those reporting RFM in the stillbirth group (mean 9.03) and those with RFM in the control group (mean 7.23) $(p=0.02)$. Further, in contrast to the findings of Winje et al. [31] which found no correlation with placental pathology and RFM, we found that changes of fetal vascular malperfusion, chorangiosis and delayed maturation of the villi were all seen more frequently in cases reporting RFM particularly within the stillbirth group.

These findings suggest the presence of a subgroup of fetuses at risk of stillbirth where mothers report RFM with a high BW:PW. This subgroup is at greater risk of agerelated ischaemic type change as the already small placenta is put under strain by the third trimester fetal growth. This highlights the possibility of RFM acting as a sign of intra uterine compromise.

The implication of this study would be to consider induction of labour in women reporting multiple episodes of RFM where the baby is large in relation to the placental size. But how should such women be selected and how will clinicians identify small placental size relative to predicted fetal birth weight? 
Improved understanding of the fetoplacental unit is required in order to examine how and when this unit is critically compromised. There have been few studies looking at placental reserve markers in the aging placenta in the clinical setting and its relationship to fetal death [32]. Dutton et al. [33] demonstrated that serum human placental lactogen was closely related to placental weight; therefore basing delivery on placental hormone levels may be an option though Heazell et al. [34] concluded that there was insufficient evidence to draw a conclusion about the efficacy of such an approach. Further studies are required, to assess markers or early predictors of falling placental reserve alongside assessment of placental size relative to body weight in patients reporting reduced fetal movements. This might include specific placental biomarkers (e.g. placental growth factor (PIGF), human chorionic gonadotrophin (hCG), plasma protein A (PAPP-A), placental protein 13 (PP-13), pregnancy-specific glycoproteins and progesterone metabolites) alongside USS evaluation of fetal weight.

\section{Strengths}

Placental pathology was reviewed alongside BW:PW in the study group and compared with matched controls. Neuropathology was included as a marker of intrauterine hypoxia. Cases came from four local health boards and hospitals which reduces the effect of local policies on decision making. The stillbirth post-mortem rate was high with $>90 \%$ of stillbirths undergoing autopsy which serves to mitigate against selection bias. Access to electronic records allowed us to fully screen our control group.

\section{Limitations}

As this was a retrospective study, data sets were not always complete particularly with regard to recording detailed placental pathology in the control group. The placentas from the control group were fixed in paraffin and thus the weight needed to be corrected based on best available evidence. Future studies in this field would benefit from comparison of fresh placentas for both groups. We accept that this is a small study and the subjective nature of perceived RFM will require a larger study to achieve reasonable confidence levels for results.

\section{Conclusions}

Our study suggests that an ability to accurately assess placental weight and functionality in relation to infant birth weight and recording of perceived RFM may help to identify a sub-group of non-dysmorphic and non-growth restricted infants at risk of stillbirth. Timely and appropriate intervention $\geq 38$ weeks could be guided by a better understanding of this phenomenon. The use and identification of biomarkers associated with falling placental reserve at $\geq 38$ weeks and assessment of placental and fetal weight by MRI or USS might provide further insight into this phenomenon and allow us to identify this "at risk" group. This paper may help to inform future research.

Acknowledgements With thanks to Dr K McKenzie who performed some of the autopsies in this study and to Prof C Smith who provided the neuropathology reports.

Funding This research did not receive any specific grant from funding agencies in the public, commercial, or not-for-profit sectors.

\section{Compliance with ethical standards}

Conflict of interest The authors declare that they have no conflict of interest.

Open Access This article is licensed under a Creative Commons Attribution 4.0 International License, which permits use, sharing, adaptation, distribution and reproduction in any medium or format, as long as you give appropriate credit to the original author(s) and the source, provide a link to the Creative Commons licence, and indicate if changes were made. The images or other third party material in this article are included in the article's Creative Commons licence, unless indicated otherwise in a credit line to the material. If material is not included in the article's Creative Commons licence and your intended use is not permitted by statutory regulation or exceeds the permitted use, you will need to obtain permission directly from the copyright holder. To view a copy of this licence, visit http://creativecommons. org/licenses/by/4.0/.

\section{References}

1. National Records of Scotland. Vital Events Reference Tables 2018 [Internet]. 2019. https://www.nrscotland.gov.uk/sta tistics-and-data/statistics/statistics-by-theme/vital-events/generalpublications/vital-events-reference-tables/2018/section-4-still births-and-infant-deaths\%0D.

2. Pásztor N, Keresztúri A, Kozinszky Z, Pál A. Identification of causes of stillbirth through autopsy and placental examination reports. Fetal Pediatr Pathol. 2014;33(1):49-54.

3. Ptacek I, Sebire NJ, Man JA, Brownbill P, Heazell AEP. Systematic review of placental pathology reported in association with stillbirth. Placenta. 2014;35:552-62.

4. Flenady V, Wojcieszek AM, Middleton P, Ellwood D, Erwich JJ, Coory $\mathrm{M}$, et al. Stillbirths: recall to action in high-income countries. Lancet. 2016;387(10019):691-702.

5. Hasegawa J, Arakawa K, Nakamura M, Matsuoka R, Ichizuka K, Katsufumi O, et al. Analysis of placental weight centiles is useful to estimate cause of fetal growth restriction. J Obs Gynaecol Res. 2011;37(11):1658-62.

6. Office of National Statistics. Overview of the UK populationOffice for National Statistics. Office for National Statistics. 2018.

7. Draper ES, Kurinczuk JJ, Kenyon S. Maternal, Newborn and Infant Clinical Outcome Review Programme MBRRACE-UK perinatal confidential enquiry: Term, singleton, normally formed, antepartum stillbirth [Internet]. 2015. https://www.npeu.ox.ac.uk/ 
downloads/files/mbrrace-uk/reports/MBRRACE-UK Perinatal Report 2015.pdf.

8. Huang DY, Usher RH, Kramer MS, Yang H, Morin L, Fretts RC. Determinants of unexplained antepartum fetal deaths. Obstet Gynecol. 2000;95(2):215-21.

9. Rasmussen S, Albrechtsen S, Irgens LM, Dalaker K, MaartmannMoe H, Vlatkovic L, et al. Risk factors for unexplained antepartum fetal death in Norway 1967-1998. Early Hum Dev. 2003;71(1):39-52.

10. Barker DJP, Thornburg KL. Placental programming of chronic diseases, cancer and lifespan: a review. Placenta. 2013;34(10):841-5.

11. Godfrey KM, Barker DJP. Fetal nutrition and adult disease. Am J Clin Nutr. 2000;71(5):1344S-52S.

12. Pásztor N, Sikovanyecz J, Keresztúri A, Kozinszky Z, Németh G. Evaluation of the relation between placental weight and placental weight to foetal weight ratio and the causes of stillbirth: a retrospective comparative study. J Obstet Gynaecol (Lahore). 2018;38(1):74-80.

13. Heazell AEP, Weir CJ, Stock SJE, Calderwood CJ, Burley SC, Froen JF, et al. Can promoting awareness of fetal movements and focusing interventions reduce fetal mortality? A stepped-wedge cluster randomised trial (AFFIRM). BMJ Open. 2017;7(8):e014813.

14. Norman JE, Heazell AEP, Rodriguez A, Weir CJ, Stock SJE, Calderwood CJ, et al. Awareness of fetal movements and care package to reduce fetal mortality (AFFIRM): a stepped wedge, cluster-randomised trial. Lancet. 2018;392:1629-38.

15. Pinar H, Iyigun $M$. A comparison of stillborn birth weights and postmortem weights. Pediatr Dev Pathol. 2010;13(6):442-6.

16. (NICE) NI of $\mathrm{H}$ and CE. Intrapartum care for healthy women and babies (update Febrary 2017). NICE guidelines. 2014.

17. Khong TY, Mooney EE, Ariel I, Balmus NCM, Boyd TK, Brundler MA, et al. Sampling and definitions of placental lesions Amsterdam placental workshop group consensus statement. Arch Pathol Lab Med. 2016;140(7):698-713.

18. Redline RW. Classification of placental lesions. Am J Obstet Gynecol. 2015;213(4):S21-5.

19. Man J, Hutchinson JC, Heazell AE, Ashworth M, Jeffrey I, Sebire NJ. Stillbirth and intrauterine fetal death: role of routine histopathological placental findings to determine cause of death. Ultrasound Obstet Gynecol. 2016;48(5):579-84.

20. Flenady V, Frøen JF, Pinar H, Torabi R, Saastad E, Guyon G, et al. An evaluation of classification systems for stillbirth. BMC Pregnancy Childbirth. 2009;9:24.

21. Moghimi A, Prakash S, Dow C, Kostos P. The effect of immersion formaldehyde fixation on placental weight. Pathology. 2014;46:S75.
22. Fox GE, Van Wesep R, Resau JH, Sun CCJ. The effect of immersion formaldehyde fixation on human placental weight. Arch Pathol Lab Med. 1991;115(7):726-8.

23. Villar J, Ismail LC, Victora CG, Ohuma EO, Bertino E, Altman DG, et al. International standards for newborn weight, length, and head circumference by gestational age and sex: the Newborn Cross-Sectional Study of the INTERGROWTH-21st Project. Lancet. 2014;384(9946):P857-68.

24. Faye-Petersen OM, Ernst LM. Maternal floor infarction and massive perivillous fibrin deposition. Surg Pathol Clin. 2013;6:101-14.

25. Redline RW. Distal villous immaturity. Diagn Histopathol. 2012;18(5):189-94.

26. Wallace JM, Horgan GW, Bhattacharya S. Placental weight and efficiency in relation to maternal body mass index and the risk of pregnancy complications in women delivering singleton babies. Placenta. 2012;33(8):611-8.

27. Almog B, Shehata F, Aljabri S, Levin I, Shalom-Paz E, Shrim A. Placenta weight percentile curves for singleton and twins deliveries. Placenta. 2011;32(1):58-62.

28. Hutcheon JA, McNamara H, Platt RW, Benjamin A, Kramer MS. Placental weight for gestational age and adverse perinatal outcomes. Obstet Gynecol. 2012;119(6):1251-8.

29. Janthanaphan M, Kor-Anantakul O, Geater A. Placental weight and its ratio to birth weight in normal pregnancy at Songkhlanagarind Hospital. J Med Assoc Thail. 2006;89(2):130-7.

30. Warrander LK, Batra G, Bernatavicius G, Greenwood SL, Dutton $\mathrm{P}$, Jones RL, et al. Maternal perception of reduced fetal movements is associated with altered placental structure and function. PLoS ONE. 2012;7(4):e34851.

31. Winje BA, Roald B, Kristensen NP, Frøen JF. Placental pathology in pregnancies with maternally perceived decreased fetal movement: a population-based nested case-cohort study. PLoS ONE. 2012;7(6):e39259.

32. Maiti K, Sultana Z, Aitken RJ, Morris J, Park F, Andrew B, et al. Evidence that fetal death is associated with placental aging. Am J Obstet Gynecol. 2017;217(4):441.e1-14.

33. Dutton PJ, Warrander LK, Roberts SA, Bernatavicius G, Byrd LM, Gaze D, et al. Predictors of poor perinatal outcome following maternal perception of reduced fetal movements: a prospective cohort study. PLoS ONE. 2012;7(7):e39784.

34. Heazell AE, Whitworth M, Duley L, Thornton JG. Use of biochemical tests of placental function for improving pregnancy outcome. Cochrane Database Syst Rev. 2015;11:1465-858. https://doi.org/10.1002/14651858.CD011202.pub2.

Publisher's Note Springer Nature remains neutral with regard to jurisdictional claims in published maps and institutional affiliations. 